\title{
Predicting youth participation in urban agriculture in Malaysia: insights from the theory of planned behavior and the functional approach to volunteer motivation
}

\begin{abstract}
This study examines factors associated with the decision of Malaysian youth to participate in a voluntary urban agriculture program. Urban agriculture has generated significant interest in developing countries to address concerns over food security, growing urbanization and employment. While an abundance of data shows attracting the participation of young people in traditional agriculture has become a challenge for many countries, few empirical studies have been conducted on youth motivation to participate in urban agriculture programs, particularly in non-Western settings. Drawing on the theories of planned behavior and the functional approach to volunteer motivation, we surveyed 890 students from a public university in Malaysia about their intention to join a new urban agriculture program. Hierarchical regression findings indicated that the strongest predictor of participation was students' attitude toward urban agriculture, followed by subjective norms, career motives and perceived barriers to participation. The findings from this study may provide useful information to the university program planners in Malaysia in identifying mechanisms for future students' involvement in the program.
\end{abstract}

Keyword: Functional approach; Theory of planned behaviour; Urban agriculture; Volunteer motivation; Youth participation 